\title{
Preliminary analysis of teleseismic receiver functions of the Ningxia and its adjacent area*
}

\author{
Xiaoqing $\mathrm{Xu}^{1} \quad$ Xuzhang Shen ${ }^{2, \uparrow}$ Chang Ming ${ }^{1}$ \\ Guofu Luo ${ }^{1}$ and Yao Lin ${ }^{1}$ \\ ${ }^{1}$ Earthquake Administration of Ningxia Hui Autonomous Region, Yinchuan 750001, China \\ ${ }^{2}$ Lanzhou Institute of Seismology, China Earthquake Administration, Lanzhou 730000, China
}

\begin{abstract}
The teleseismic receiver functions of digital seismic network of Ningxia and its adjacent area are calculated with two different Gauss filter factors. The accuracy and stability of the receiver functions are discussed. The $h-k$ stacking method is applied to estimate the crustal thickness and velocity ratio beneath seismic stations. The results indicate that there are sharp changes of crustal thickness and velocity ratio in the studied region. This region is located in the northeastern margin of Tibet, and also a junction of several first-grade blocks. The large contrast of crustal structure in this region is considered to be resulted from the interaction of these blocks. Our results are helpful to construct the completed model of the formation and evolution of the Tibet. Some local structures are also discussed combining with the geological faults.
\end{abstract}

Key words: receiver function; Ningxia; crustal thickness; velocity ratio CLC number: P315.3 $3^{+}$Document code: A

\section{Introduction}

Ningxia is located in the center of China, which also belongs to the northern section of North-South Seismic Zone. Most part of the Ningxia is also in the margin fault belt of the western Ordos basin, which is close to eastern Qilianshan orogenic belt in west, close to Alxa block in north and adjacent to north of western Qinling tectonic belt in south and the previous studies indicated that the geological structure and evolution are very complicated in this region (Huo, 1993; Liu and Liu, 2011).

From 1970s, Lanzhou Institute of Seismology, China Earthquake Administration and other institutions sequentially have finished several magnetotelluric detection works in Ningxia and its adjacent area. In the 1980s, the State Seismological Bureau (1992a, b)

\footnotetext{
* Received 7 October 2011; accepted in revised form 9 January 2012; published 10 February 2012.

* Corresponding author. e-mail: shenxzh@gmail.com

(c) The Seismological Society of China, Institute of Geophysics, China Earthquake Administration, and Springer-Verlag Berlin Heidelberg 2012
}

organized and completed two large cross sections of research region, and got the results of two-dimensional velocity structure of crust beneath Yinchuan graben. In recent years, the Geophysical Exploration Center, China Earthquake Administration completed two seismic section profiles: Maqing-Lanzhou-Jingbian and XijiZhongwei sections (Li et al., 2001, 2002). Xie et al. (2010) used seven regional digital seismic stations to calculate receiver functions, their result indicated that the average crustal thickness beneath Ningxia is about $46 \mathrm{~km}$. Ma et al. (2010) analyzed the earthquakes with $M \geq 6.0$ recorded by six digital seismic stations in Ningxia and obtained some results of the crustal anisotropy measurement in Ningxia region.

The waveforms recorded by Ningxia seismic network are very important for understanding the interaction of different blocks and the complicated geological phenomena below the Ningxia. By 2010, there are 19 digital seismic stations in Ningxia seismic network, some stations are constructed in recent years. In this study, we will calculate the teleseismic receiver functions of Ningxia seismic network and discuss the crustal char- 
acteristics of Ningxia and its adjacent region.

\section{Data and methods}

According to the previous study (Yang et al., 2007), the Ningxia and its adjacent area is composed of Yinchuan graben, Ordos block, Alxa block and arcu- ate tectonic junction of northeastern Tibet (shown in Figure 1a). The results from geological survey, geodetic survey and seismic source (Guo and Qin, 1979) showed that this region's principal stress axis approaches approximately from NE to ENE, which is close to the horizontal direction, and it is the most important dynamic factor in the region (Xu et al., 2000).
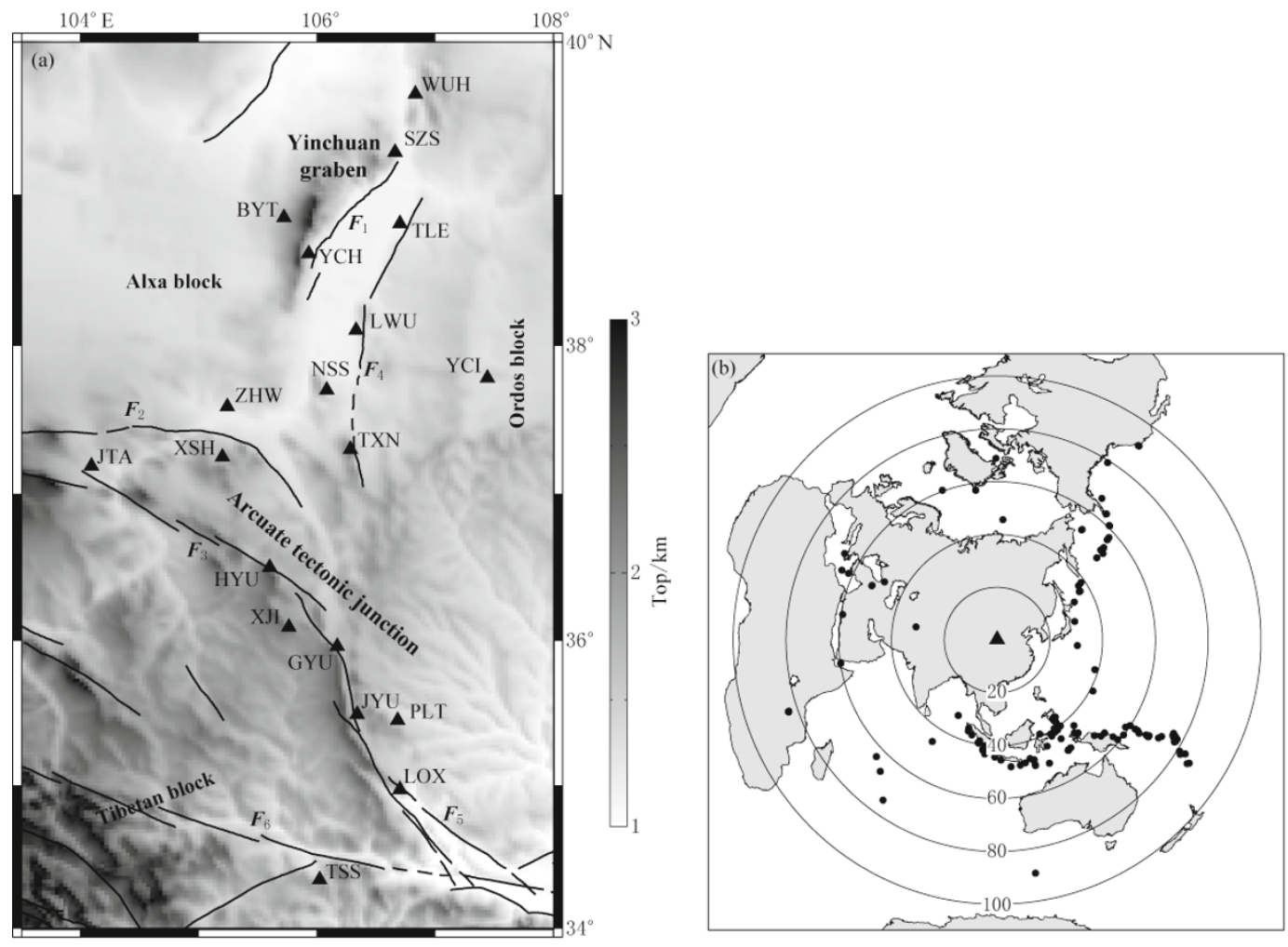

Figure 1 (a) Geological map and distribution of 19 seismic stations. The triangles represent the seismic stations. $F_{1}$. Helanshan fault; $F_{2}$. Xiangshan fault; $F_{3}$. Haiyuan fault; $F_{4}$. Eastern Luoshan fault; $F_{5}$. Liupanshan fault; $F_{6}$. Western Qinling fault. (b) Distribution of stations and epicenters. The triangles represent the seismic stations, and circles stand for epicenters.

\subsection{Observed receiver functions}

Our research data comes both from seismic waveforms recorded by 19 digital broadband seismic stations in Ningxia and its adjacent area and earthquake catalogs coming from the United States Geological Survey (USGS). We select the waveforms of the earthquakes with $M_{\mathrm{S}} \geq 5.5$ and epicentral distance between $30^{\circ}$ and $90^{\circ}$ during 2009 to 2010 . For every record of each station, $\mathrm{P}$ phase's real arrival time is picked up according to the theoretic value. We cut waveforms from $\mathrm{P}$ phase previous 10 seconds to $\mathrm{P}$ phase later 95 seconds. In order to make results credible and accurate, we only select the original waveforms which have high signal to noise ratio and clear $\mathrm{P}$ phase. After averaging and tilting correction for each record picked up, EW and NS components of waveforms are rotated to tangential and radial directions. By deconvolution operation (Ligorria and Ammon, 1999), tangential and radial receiver functions are obtained. Finally, we obtain about 260 teleseismic events (shown in Figure 1b) whose back azimuths are mainly concentrated in $30^{\circ}-65^{\circ}$ or $100^{\circ}-200^{\circ}$ and epicentral distances are concentrated in $30^{\circ}-80^{\circ}$.

\section{$2.2 \quad h-k$ stacking}

$\mathrm{P}$ wave will convert to $\mathrm{S}$ wave (e.g. Ps) or other multiple waves (e.g. PpPs, PsPs, PpSs) because of Moho or other discontinuities. Zhu and Kanamori (2000) 
proposed $h-k$ stacking method to quantify the Poisson's ratio and crustal thickness with Ps converted phase and multiple reflections. The result of this method is stable and has been used in many regions.

\section{Results}

The Gauss filter factor, $\alpha$, controls the bandwidth of the Gauss function. If a bigger $\alpha$ is used, more detailed information with high frequency will be included, and we can focus on what we are interested in, but many high frequency noises might interfere the signals from discontinuities. If a smaller $\alpha$ is used, the noise can be filtered effectively, but accuracy, signal to noise ratio and resolution will be lowered (Shen, 2011; Shen et al.,
2011). In this paper we use two different Gauss filter factors (1.0 and 2.5) in the deconvolution to calculate receiver functions.

According to the results from deep seismic sounding (DSS) (Li et al., 2001, 2002), we take the crustal thickness variation within $30-60 \mathrm{~km}$ with $1 \mathrm{~km}$ search step, the seismic velocity ratio ranges from 1.6 to 2.0 with 0.01 search step, $\mathrm{P}$ wave velocity is $6.2 \mathrm{~km} / \mathrm{s}$ as the velocity model, and the weight for Ps, PpPs, and PsPs (or PpSs) is $0.7,0.2$ and 0.1 for $h-k$ stacking.

Table 1 shows the $h$ - $k$ stacking results beneath each seismic station. The results of different frequencies can be used to evaluate the resolution and stability of the results. If the crustal structure is simple, the results

Table 1 Results of $h$ - $k$ stacking method

\begin{tabular}{|c|c|c|c|c|c|c|c|c|c|c|c|c|c|}
\hline \multirow{2}{*}{ Station } & \multicolumn{2}{|c|}{$\alpha=1.0$} & \multicolumn{2}{|c|}{$\alpha=2.5$} & \multicolumn{2}{|c|}{ Average } & \multirow{2}{*}{ Station } & \multicolumn{2}{|c|}{$\alpha=1.0$} & \multicolumn{2}{|c|}{$\alpha=2.5$} & \multicolumn{2}{|c|}{ Average } \\
\hline & $h$ & $k$ & $h$ & $k$ & $h$ & $k$ & & $h$ & $k$ & $h$ & $k$ & $h$ & $k$ \\
\hline WUH & 39.0 & 1.81 & 38.0 & 1.84 & 38.5 & 1.83 & JYU & 52.0 & 1.79 & 53.0 & 1.79 & 52.5 & 1.79 \\
\hline BYT & 50.0 & 1.67 & 51.0 & 1.67 & 50.5 & 1.67 & LOX & 48.0 & 1.75 & 48.0 & 1.77 & 48.0 & 1.76 \\
\hline $\mathrm{YCH}$ & 48.0 & 1.71 & 48.0 & 1.73 & 48.0 & 1.72 & TSS & 45.0 & 1.71 & 45.0 & 1.73 & 45.0 & 1.72 \\
\hline YCI & 38.0 & 1.90 & 41.0 & 1.75 & 39.5 & 1.83 & SZS & 34.0 & 2.00 & 40.0 & 1.89 & 37.0 & 1.95 \\
\hline TLE & 44.0 & 1.75 & 47.0 & 1.68 & 45.5 & 1.72 & PLT & 56.0 & 1.60 & 33.0 & 1.97 & 44.5 & 1.79 \\
\hline LWU & 46.0 & 1.75 & 50.0 & 1.67 & 48.0 & 1.71 & $\mathrm{TXN}$ & 39.0 & 2.00 & 39.0 & 2.00 & 39.0 & 2.00 \\
\hline JTA & 50.0 & 1.72 & 47.0 & 1.80 & 48.5 & 1.76 & $\mathrm{XSH}$ & 51.0 & 1.60 & 49.0 & 1.72 & 50.0 & 1.66 \\
\hline ZHW & 49.0 & 1.70 & 50.0 & 1.68 & 49.5 & 1.69 & NSS & 44.0 & 1.61 & 30.0 & 1.81 & 37.0 & 1.71 \\
\hline HYU & 49.0 & 1.82 & 50.0 & 1.78 & 49.5 & 1.80 & GYU & 52.0 & 1.96 & 51.0 & 2.00 & 51.5 & 1.98 \\
\hline XJI & 53.0 & 1.79 & 54.0 & 1.79 & 53.5 & 1.79 & & & & & & & \\
\hline
\end{tabular}

from $h-k$ stacking method with different factors should be consistent. In other words, the parameter variations have less influence on a simple model. If the results from $h-k$ stacking with different filtering factors are stable or consistent, this result is more reliable than that with single frequency filter. So we use different filter factors to calculate receiver functions and try to compare the results, then evaluate the crustal characters. In this paper, $h-k$ results can be divided into two groups: (1) The crustal thickness $h$ and velocity ratio $k$ calculated with different filter factors are consistent and do not reach the boundary values, as the result of WUH station shown in Figure 2. (2) The $h$ and $k$ with different filtering factors vary greatly or reach the boundary values, as the result of PLT station shown in Figure 3. The results of six stations in Table 1 with black frame belong to the above group (2), the results of another 13 stations belong to the group (1).

According to the results of $h-k$ with two different
Gauss filter factors, we get the map of the Moho depth and the $v_{\mathrm{P}} / v_{\mathrm{S}}$ topography beneath Ningxia and its adjacent area as shown in Figure 4. The stations, whose $h-k$ results with two different Gauss filter factors are instable or reach boundary valve, are not included.

\section{Discussions}

\subsection{General characteristics of the crustal struc- ture}

Figure 4 shows the contrast of $h$ and $k$ in the study region. The crustal thickness varies from $35 \mathrm{~km}$ in the northeastern area to $55 \mathrm{~km}$ in the southwest area, while the velocity ratio varies from 2.0 to 1.6. Such sharp changes represent the intense deformation of the crust, especially the Moho. This region is located in a junction of three first-grade blocks, which is also a transition zone from Tibet to Ordos block. The complicated geological environment leads to the complicated crustal structure.

According to analysis on the topography extracted 


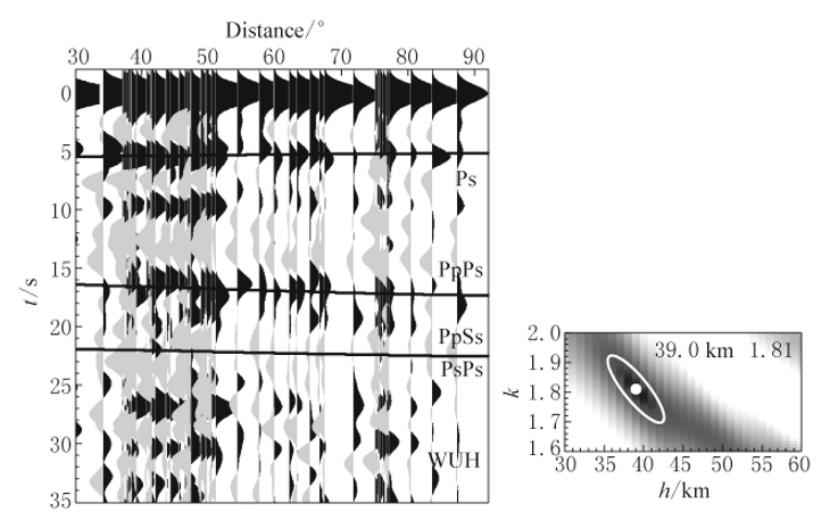

(a)
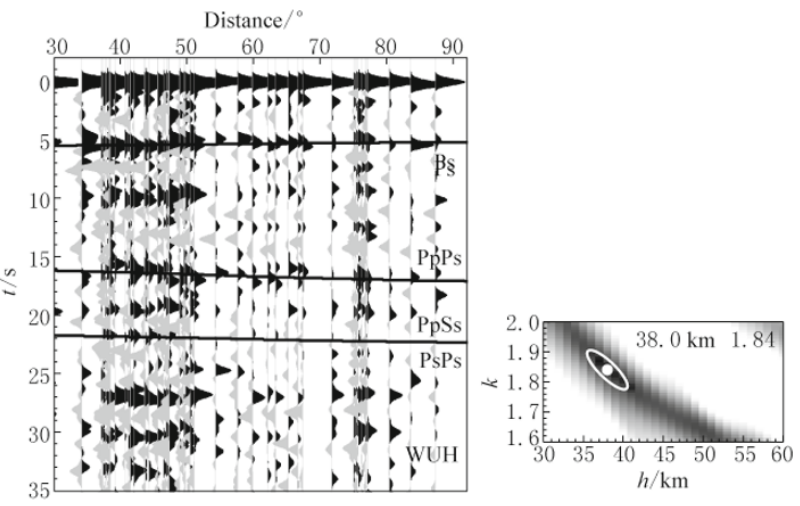

(b)

Figure 2 The results of $h-k$ stacking of station WUH with Gauss filter factors of 1.0 (a) and 2.5 (b). Black lines represent theoretical Ps, PpPs, PpSs (PsPs) phases. The numbers on right-top of each right figure are Moho depth and velocity ratio.

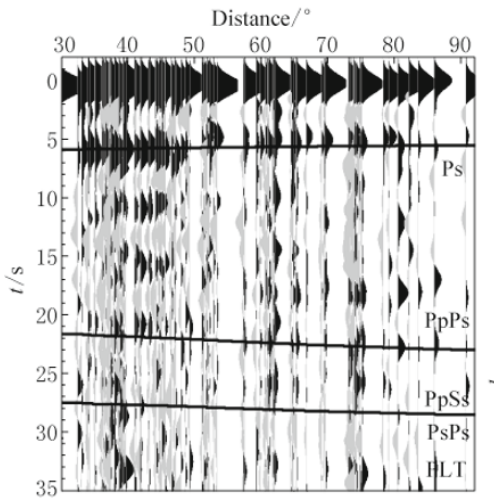

(a)

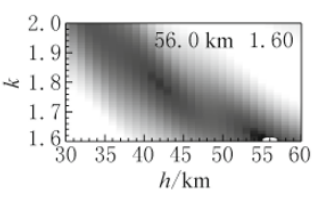

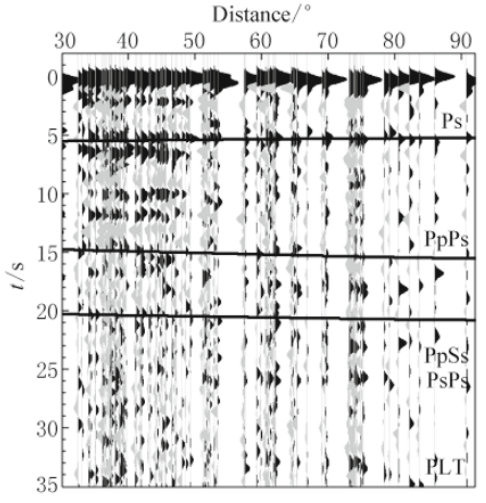

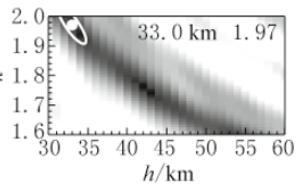

(b)

Figure 3 The results of $h-k$ stacking of station PLT with Gauss filter factors $\alpha$ of 1.0 (a) and 2.5 (b). Black lines represent theoretical Ps, PpPs, PpSs (PsPs) phases. The numbers on right-top of each right figure are Moho depth and velocity ratio.

from swath profiles along the northern, southern and eastern margins of the Tibetan plateau, Clark and Royden (2000) used the lower crust fluid channel flow to explain the large-scale morphology of eastern Tibet. According to the viewpoint of Clark and Royden (2000), the crust of Tibet is hot, while the crust in Ordos is cold and stable. But our results indicate the values of the velocity ratio of the stations near the Ordos are larger than those of the stations near the Tibet. Large velocity ratio means the hot crust, and the lower velocity value means the cold crust. This result deviates from the viewpoint of Royden et al. (2008). We think most part of our study region is located in the transitional zone from Tibet to Ordos block, the local sharp changes is also possible because of the interaction of blocks.

\subsection{Crustal structure of the Yinchuan graben and adjacent area}

In 1980s, the former State Seismological Bureau (1992a, b) organized a completely section investigation from Alxa to Dingbian city. They concluded that the Moho depth of Yinchuan graben is about 37 to $40 \mathrm{~km}$, and the mantle beneath the Yinchuan graben might uplift. From the $h-k$ stacking results of this paper, we conclude that the crustal thickness beneath the western region of Yinchuan graben (BYT) is thicker than the eastern (TLE); it is thicker in the southern (LWU) than in the northern (WUH). This phenomenon might explain that Yinchuan graben is pushed toward northeast by Tibetan and Alxa blocks. This result is also consistent with previous conclusions (Yang et al., 

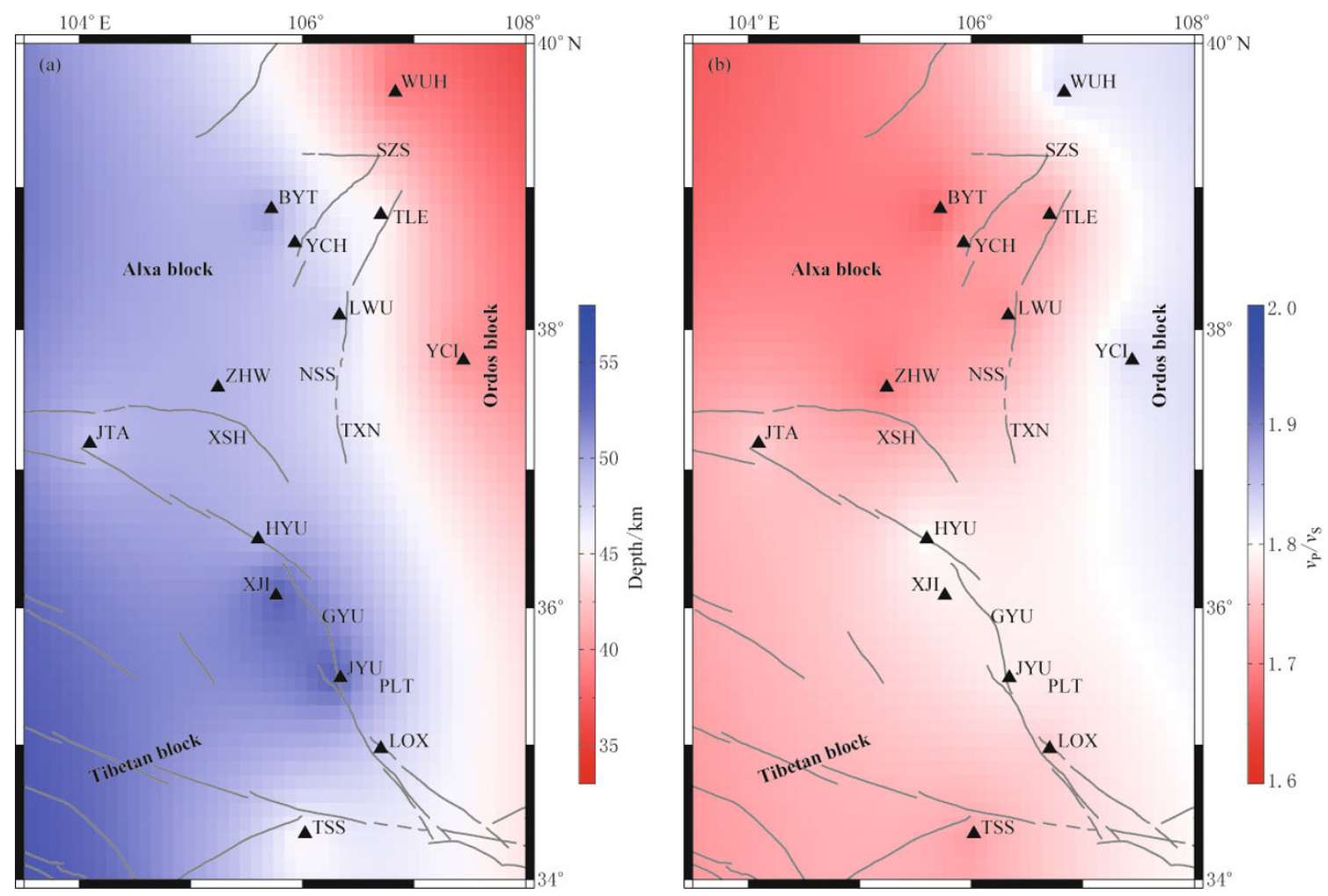

Figure 4 (a) Crustal thickness beneath Ningxia and its adjacent area. (b) Velocity ratio $v_{\mathrm{P}} / v_{\mathrm{S}}$ beneath Ningxia and its adjacent area.

2007). The crustal thickness beneath YCH station is $48 \mathrm{~km}$ in this study, and the crustal thickness beneath Yinchuan graben is about 40 to $50 \mathrm{~km}$. These results are much different from the studies obtained by the former State Seismological Bureau, which suggested as 37 to $40 \mathrm{~km}$. Gao et al. (2005) used simulated annealing algorithm and transfer function to get 61 seismic stations' crustal thickness in China and adjacent area, suggesting that the crustal thickness beneath Yinchuan is about $46 \mathrm{~km}$. Xie et al. (2010) also used $h-k$ stacking method and got the value of $45.9 \mathrm{~km}$. Therefore, it is necessary to carry out more work to determine the crustal thickness beneath Yinchuan. Whether upper mantle beneath Yinchuan graben exists upwelling of hot material needs further proof.

We try to discuss the relationship between depths of weak earthquakes in Ningxia and its adjacent area and the stability of the $h-k$ stacking results. Since 2008 , the earthquakes $\left(M_{\mathrm{L}} \geq 2.5\right.$, coming from the China Earthquake Networks Center) occurred in Ningxia and its neighboring area are selected and focal depth contours map is also considered. It is a common concept that a heterogeneous, anisotropic and brittle media, due to mixing different components, has lower hardness and is more prone to rupture. So the complicated crustal structure may be one of the reason which causes the instability of the $h$ - $k$ results and broad the depths distribution of weak earthquakes. There is another common phenomenon that there are negative signals before Pms phase in nearly all receiver functions of the 19 stations. Theses negative signals might be due to low-velocity layer in the crust. This phenomenon might indicate that there is the low-velocity layer beneath Ningxia and its adjacent area.

Today the geological stress in Ningxia and its neighboring area comes mainly from Tibet movement (Li and Zhao, 1981, 1986). The stress with ENE-WSW direction is the most important dynamic factor in this area. Yang et al. (2007) pointed out the principal stress axis is NE direction in the range of $40^{\circ}$ to $80^{\circ}$. Jiang et al. (2001) believed that the arcuate tectonic junction of the northeast Tibet has such compressed characteristic, its faults are reverse, and the crust is shortened. This may explain why the $h-k$ results show that crustal thickness in the arcuate tectonic area of the northeastern Tibetan plateau is significantly much thicker than that in the northern Ningxia (Yinchuan graben). 


\section{Conclusions}

We calculate the teleseismic receiver functions of digital seismic network of Ningxia and its adjacent area with two different Gauss filters. The conclusions are drawn as follows from the results using the $h$ - $k$ stacking method.

1) There are sharp changes of crustal thickness and $v_{\mathrm{P}} / v_{\mathrm{S}}$ ratio in the studied region. Such sharp changes represent the intense deformation of the crust and the complicated geological environment results in the large contrast of crustal structure in the region.

2) The values of the velocity ratio of the stations near the Ordos are larger than those of the stations near the Tibet. We think most part of our study region is located in the transitional zone from Tibet to Ordos block, the local sharp changes is also possible because of the interaction of blocks.

3) The crustal thickness beneath Yinchuan is obtained as $48 \mathrm{~km}$, which is much different from precious studies suggested as 37 to $40 \mathrm{~km}$. So the viewpoint of the upwelling of hot material in the upper mantle of Yinchuan graben should be further confirmed with more information.

4) The low-velocity zone might exist in the crust beneath Ningxia and its adjacent area. The complicated crustal structure may be one of the reasons that cause the instability of the $h-k$ results and broad depths distribution of weak earthquakes.

Acknowledgements The anonymous reviewers reviewed the paper carefully and provided many detailed suggestions. Some figures were plotted with General Mapping Tools (Wessel and Smith, 1995). This work was financially supported by the basic research and development fund from Institute of Earthquake Science, China Earthquake Administration (grant No. 2011IESLZ05) and the National Natural Science Foundation of China (grant No. 40904014). The authors gratefully acknowledge all of them.

\section{References}

Clark M K and Royden L H (2000). Topographic ooze: building the eastern margin of Tibet by lower crustal flow. Geology 28: 703-706.

Gao X, Wang W M and Yao Z X (2005). Crustal structure of China mainland and its adjacent regions. Chinese J Geophys 48: 591-601 (in Chinese with English abstract).

Guo Z J and Qin B Y (1979). Seismic Source Physics. Seismological Press, Beijing, 104-108 (in Chinese).

Huo F C (1993). Ningxia geological summary. Acta Geo- logica in Gansu 31: 101-133 (in Chinese with English abstract).

Jiang Z S, Ding P and Wang S X (2001). Western Land Deformation Monitoring and Earthquake Prediction in China. Seismological Press, Beijing, 87-90 (in Chinese).

Li M L and Zhao Z J (1981). Focal mechanism and stress filed of Ningxia region. Northwestern Seismological Journal 3: 49-55 (in Chinese with English abstract).

Li M L and Zhao Z J (1986). Modern tectonic stress field and its relation with seismicities in Ningxia and its neighborhood. Journal of Seismological Research 9: 299-314 (in Chinese with English abstract).

Li S L, Zhang X K and Ren Q G (2001). Seismic sounding profile and its interpretation in the region of XijiZhongwei. Seismology and Geology 23(1): 356-370 (in Chinese with English abstract).

Li S L, Zhang X K and Zhang C K (2002). A preliminary study on the crustal velocity structure of MaqingLanzhou-Jingbian by means of deep seismic sounding profile. Chinese J Geophys 45: 210-217 (in Chinese with English abstract).

Ligorria J and Ammon C (1999). Iterative deconvolution and receiver function estimation. Bull Seismol Soc Am 89: 1 395-1 400.

Liu M and Liu Z J (2011). Structural unit partition and favorable evaluation of oil and gas exploration area in Ningxia. Petrochemical Industry Application 30: 65-68 (in Chinese with English abstract).

Ma H Q, Ding Z J, Chang L J, Gao W P and Cai X H (2010). Seismic anisotropy of the upper mantle in Ningxia region. Acta Seismologica Sinica 32: 507-516 (in Chinese with English abstract).

Rodyen L H, Burchfiel B C and van der Hilst R D (2008). The geologic evolution of the Tibetan Plateau. Science 321: $1054-1058$.

Shen X Z (2011). Study on the low-velocity discontinuity at the depth of $170 \mathrm{~km}$ beneath SSE station in Shanghai, China. Chinese J Geophys 3: 698-705 (in Chinese with English abstract).

Shen X Z, Mei X P and Yang H (2011). Study on the crustal structures beneath Wenchuan earthquake rupture zone. Progress in Geophys 2: 477-488 (in Chinese with English abstract).

State Seismological Bureau (1992a). The Geoscience Transect from Shanghai Fengxian to Inner Mongolia Alxa. Seismological Press, Beijing, 1-3 (in Chinese).

State Seismological Bureau (1992b). The Geoscience Transect from Qinghai Menyuan to Fujian Ningde. Seismological Press, Beijing, 4-11 (in Chinese).

Wessel P and Smith W HF (1995). New version of the generic mapping tools released. Eos Trans Am Geophys Union 76: 329.

Xie X F, Chong J J, Liu Y Y and Yao L (2010). Inversing the Crustal Thickness in Ningxia area by H-Kappa 
method. Journal of Seismological Research 33: 309-313 (in Chinese with English abstract).

Xu W J, Zhao W M, Chai C Z and Jin Y L (2000). Establishment of the GPS monitoring network in the middle part of Ningxia and preliminary study of relationship between the crustal deformation and the stress field and seismicity. Earthquake Research in China 1: 44-55 (in Chinese with English abstract)

Yang M Z, Ma H Q and Liao Y H (2007). Ningxia Seismic Activity Research. Seismological Press, Beijing, 10-40 (in Chinese).

Zhu L and Kanamori H (2000). Moho depth variation in southern California from teleseismic receiver functions. J Geophys Res 105: 2 969-2 980. 